\title{
Thermal, mechanical and microstructural analysis of concrete containing microencapsulated phase change materials
}

\author{
Pejman Keikhaei Dehdezi ${ }^{\mathrm{a}, \mathrm{b}}{ }_{*}$, Matthew R. Hall ${ }^{\mathrm{b}}$, Andrew R. Dawson ${ }^{\mathrm{a}}$ and Sean P. Casey ${ }^{\mathrm{b}}$ \\ ${ }^{a}$ Division of Infrastructure and Geomatics, Faculty of Engineering, Nottingham Transport Engineering Centre, University of Nottingham, \\ University Park, Nottingham NG7 2RD, UK, ${ }^{b}$ Division of Materials, Mechanics and Structures, Faculty of Engineering, Nottingham \\ Centre for Geomechanics, University of Nottingham, University Park, Nottingham NG7 2RD, UK
}

(Received 25 July 2011; final version received 26 July 2012)

\begin{abstract}
This paper studies the thermal, mechanical and microstructural aspects of concrete containing different amounts of microencapsulated phase change materials (PCMs). In addition, numerical simulation is carried out to study the potential application of PCM-modified concrete for reduction in summer surface temperature. It is shown that increasing PCM content in concrete led to lower thermal conductivity and an increase in the heat storage ability of concrete. However, the compressive and flexural strength of concrete significantly decreased. Microstructural analysis showed that PCMs appear to remain intact during mixing; however, PCM particles appear to fail by bursting under loading, creating hemispherical voids and crack initiation points as well as possible entrapped air behaviour. The result of numerical simulation revealed that reduction in summer concrete pavement surface temperature by several degrees was possible, with implications for reduction in concrete thermal stresses, shrinkage and urban heat island effect.
\end{abstract}

Keywords: concrete pavement; SEM; thermal analysis; modelling; phase change materials

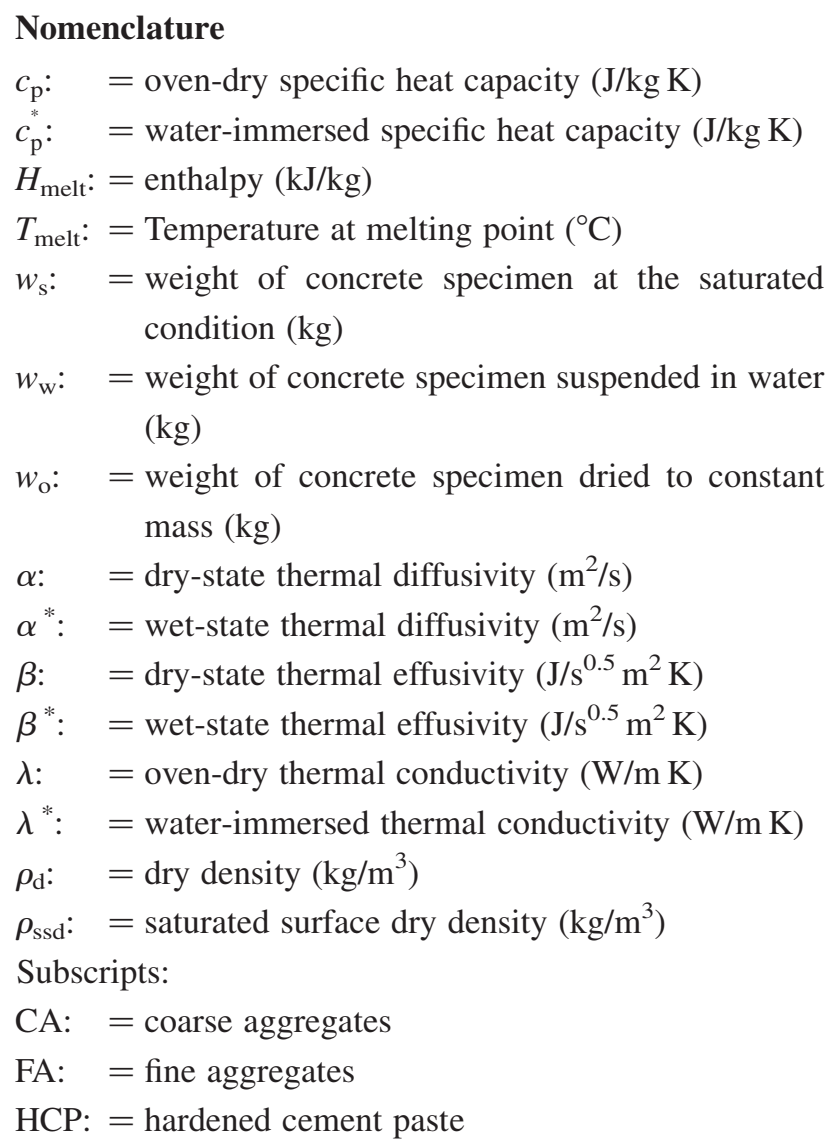

\section{Introduction}

Thermal energy storage technologies can be divided into two categories: sensible and latent (Mehling and Cabeza 2008). Sensible heat storage is by far the most common method for heat storage, which is done by changing the temperature of a storage material, for example high-grade heat storage (e.g. hot water and steam) or low-grade heat storage (e.g. ground source). Heat may also be absorbed, stored or released from a material at almost constant temperature due to the high latent enthalpy of solid-liquid phase change. Phase change materials (PCMs) have a narrow characteristic temperature range over which melting occurs, and which can be selected to suit operating temperatures in several engineering applications. These chiefly apply to transient operating conditions in which the PCM can enhance buffering of $\mathrm{max} / \mathrm{min}$ temperature variations about the mean (Cabeza et al. 2007, Tyagi and Buddhi 2007, Mehling and Cabeza 2008, Baetens et al. 2010), or attenuation and delay of peak temperature occurrence (Bentz and Turpin 2007, Hunger et al. 2009, Castell et al. 2010, Karlessi et al. 2011). Containment of the liquid-phase PCM can be achieved by various encapsulation methods (Mehling and Cabeza 2008), and more recently by microencapsulation inside polymeric pellets, typically $\sim 50 \mu \mathrm{m}$ diameter, which can be either in bulk powder form or in colloidal suspension (BayésGarcía et al. 2010).

A small number of studies have focused on applications relating to concrete incorporating PCMs for fabric energy

\footnotetext{
*Corresponding author. Email: evxpk3@nottingham.ac.uk

ISSN 1029-8436 print/ISSN 1477-268X online

(C) 2012 Taylor \& Francis

http://dx.doi.org/10.1080/10298436.2012.716837

http://www.tandfonline.com
} 
storage (e.g. in walls) for increasing thermal comfort and reducing peak cooling loads in buildings (Zhang et al. 2004, Cabeza et al. 2007, Hunger et al. 2009, Baetens et al. 2010, Entrop et al. 2011). Cabeza et al. (2007) presented an experimental study of two full-size concrete test buildings, one of which included $5 \mathrm{wt} \%$ microencapsulated PCM $\left(T_{\text {melt }}=26^{\circ} \mathrm{C}\right)$ in the concrete walls. Both test buildings were fully instrumented, by installing temperature sensors in every wall and in the middle of the room, to monitor and evaluate the thermal characteristics. The concrete room without PCM had a maximum indoor dry bulb air temperature of about $2^{\circ} \mathrm{C}$ higher than the room with PCM, and a minimum temperature of $2^{\circ} \mathrm{C}$ lower. Bentz and Turpin (2007) proposed the idea of using PCM-modified concrete to reduce the number of freeze/thaw cycles in concrete bridge decks. They showed, by numerical simulations, that $15 \mathrm{wt} \%$ microencapsulated PCM-modified concrete $\left(H_{\text {melt }}=250 \mathrm{~kJ} / \mathrm{kg}, T_{\text {melt }}=5^{\circ} \mathrm{C}\right)$ could potentially reduce the number of freeze/thaw cycles by up to $\sim 30 \%$ compared to a plain concrete (control). Hunger et al. (2009) investigated the mixing rheology, hydration and post-hardening properties of self-compacting concrete modified with microencapsulated PCM. Numerical modelling and experimental results showed that the peak hydration temperature could be reduced by up to $\sim 28 \%$ with $5 \mathrm{wt} \%$ PCM addition. Entrop et al. (2011) studied the use of microencapsulated PCMs to store solar energy in concrete floors and to save energy in Dutch houses. They experimentally compared the floor temperature variations in a control concrete and in a $5 \mathrm{wt} \%$ PCM-modified concrete $\left(H_{\text {melt }}=110 \mathrm{~kJ} / \mathrm{kg}, T_{\text {melt }}=23^{\circ} \mathrm{C}\right)$ and concluded that the application of PCMs in concrete floors resulted in a reduction in maximum floor temperatures up to $16 \pm 2 \%$ and an increase in minimum temperatures up to $7 \pm 3 \%$. Karlessi et al. (2011) experimentally studied the potential of using concrete coated with $30 \mathrm{wt} \%$ PCM $\left(H_{\text {melt }}=180\right.$ $\mathrm{kJ} / \mathrm{kg}, T_{\text {melt }}=18,24,28^{\circ} \mathrm{C}$ ), when used in the exterior of buildings, to reduce and delay the peak heat load while reducing room temperature fluctuation. They monitored the surface temperature of the common coatings with that of the PCM coating for a period of 30 days in summer. They found that PCM coatings present lower surface temperatures than common coatings of the same colour in a range of $3-7.5^{\circ} \mathrm{C}$. Other applications for PCM-modified concrete could include selective modification of concrete pavement surface temperature. Reduction in summer surface temperature, for example, could reduce shrinkage and thermal stresses (e.g. curling, warping and so on), or minimise the urban heat island effect. Increased pavement surface temperature in winter could avoid or inhibit surface freezing in some climates.

Although the benefits of PCM-modified concrete appear very promising, it can also have a negative effect on mechanical performance of the concrete. A limited number of studies have investigated the source of this behaviour (Hunger et al. 2009), and found that significant changes occur at the microstructural scale even for relatively low concentrations of microencapsulated PCM addition. Clearly, more research is required to (i) better understand and identify the microstructural phenomena relating to changes in mechanical performance and (ii) to analyse the trade-off between desired thermo-physical enhancements and mechanical properties, i.e. when is it worth using PCM and how much should be used? The investigation reported in this study focused on plain and PCM-modified concrete and the objectives were to:

- Characterise its thermo-physical properties (thermal conductivity, heat capacity, thermal diffusivity and thermal effusivity) in both the dry state and fully saturated. This was done by carrying out laboratory experiments to measure thermal, physical and mechanical properties of PCM-modified concrete, and results are presented in Sections 3 and 4.

- Determine its mechanical properties [compressive and flexural strength, density, porosity and ultrasonic pulse velocity (UPV)] by carrying out mechanical test on concrete specimens. These results are presented in Section 4.

- Determine the extent to which microstructural differences are the cause of the change in thermal and mechanical properties when PCM is added. This was carried out by microstructural analysis using scanning electron microscopy (SEM) with energy dispersive X-ray spectrometry (EDS) analysis of the:

- Microencapsulated PCM powder (morphology and particle size distribution), and characteristics of fresh and mechanically damaged particles.

- Interface between PCM particles and hardened aggregate/cement matrix. The results for these analyses are presented in Section 5.

- Show how the addition of PCM is likely to induce temperature responses of the material when used in typical applications. This is done by comparing numerical simulation of surface and cross-sectional temperature evolution in a control concrete and in a PCM-modified concrete pavements. The results of this simulation are presented in Section 6.

\section{Materials, mix design and sample preparation}

The control mix for concrete comprised a 10/20 (lower/upper sieve sizes)-sized limestone aggregate and $4 \mathrm{~mm}$ down natural sand in compliance with BS EN 12620 (2008) with high-strength Portland cement (CEM I class, $52.5 \mathrm{~N} / \mathrm{mm}^{2}$ ). The PCM was a microencapsulated paraffin wax in the form of a dry powder (supplied by CIBA Specialty Chemicals, Bradford, UK) comprising an acrylic outer shell, where $T_{\text {melt }}=26^{\circ} \mathrm{C}$ and $H_{\text {melt }}=160 \mathrm{~kJ} / \mathrm{kg}$. The PCM particle diameter was found to typically range 
from approximately 20 to $80 \mu \mathrm{m}$, as shown in Figure 1 . The approximate diameter range was determined by the authors through measurements by eye from secondary electron (SE) micrographs at $250 \times$ magnification. The accelerating voltage, working distance, detector type (SE) and spot size are already given on the scale bar as shown in Figure 1. The control mix was modified to produce four more mixes containing $0.5 \mathrm{wt} \%, 1 \mathrm{wt} \%, 3 \mathrm{wt} \%$ and $5 \mathrm{wt} \%$ of PCM powder, based on total mass of mix constituents, as shown in Table 1. The PCM powder was replaced by the $0-600 \mu \mathrm{m}$ sand fraction in the concrete mix. That is because the volume of PCM that was needed in order to replace the sand was more than the volume of $20-80 \mu \mathrm{m}$ sand, therefore, a larger volume of sand was needed to be removed. All concrete specimens were compacted using a vibration table and air-cured for $24 \mathrm{~h}$ in laboratory conditions, before de-moulding and water curing for a period of 28 days at a temperature of $20 \pm 2^{\circ} \mathrm{C}$.

\section{Porosity and mechanical properties}

Five $100 \mathrm{~mm}$ cubes per mix were used for the determination of compressive strength at 28 days [according to BS EN 12390-3 (2009c)], and the results are presented in Figure 2. It can be clearly observed that increasing PCM dosage leads to significant reductions in compressive strength. The percentage reductions in strength are approximately $25 \%, 45 \%, 70 \%$ and $80 \%$ for $0.5 \%, 1 \%, 3 \%$ and 5\% PCM replacement, respectively.

Apparent porosity (AP) of specimens was assessed using the following expression:

$$
\operatorname{AP}(\%)=\frac{w_{\mathrm{s}}-w_{\mathrm{o}}}{w_{\mathrm{s}}-w_{\mathrm{w}}} \times 100 .
$$

Concrete density was determined according to EN 12390-7 (2009b). Figure 3 shows the influence of PCM addition on the dry density and AP of the concrete mix. The overall density reduction in the modified concrete

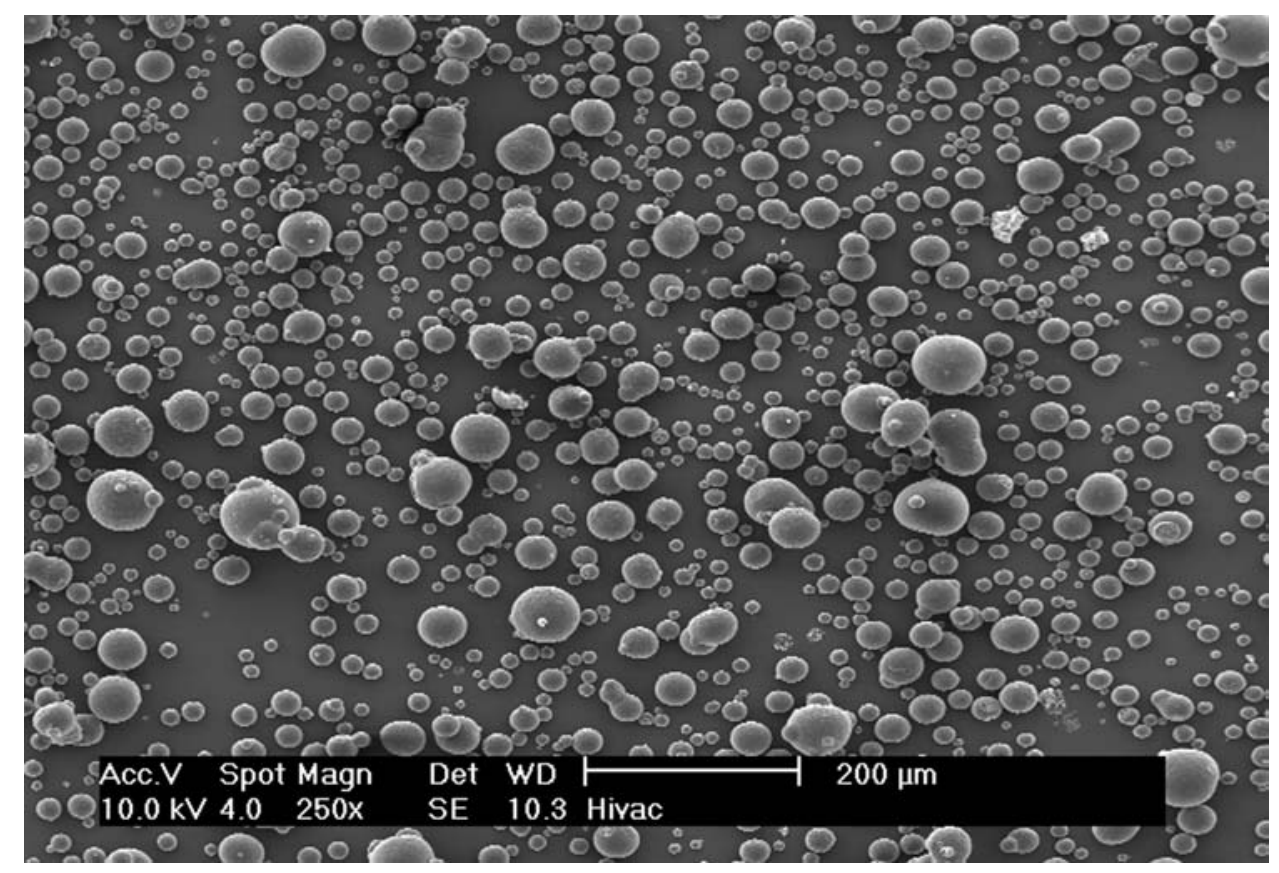

Figure 1. Particle size distribution of microencapsulated PCM.

Table 1. Mix design (total volume: $1 \mathrm{~m}^{3}$ ).

\begin{tabular}{|c|c|c|c|c|c|c|c|c|c|c|}
\hline & \multicolumn{2}{|c|}{ Reference mix } & \multicolumn{2}{|c|}{$0.5 \%$ Mix } & \multicolumn{2}{|c|}{$1 \% \mathrm{Mix}$} & \multicolumn{2}{|c|}{$3 \%$ Mix } & \multicolumn{2}{|c|}{$5 \%$ Mix } \\
\hline & $\begin{array}{l}\text { Volume } \\
\left(\mathrm{m}^{3}\right)\end{array}$ & $\begin{array}{l}\text { Mass } \\
(\mathrm{kg})\end{array}$ & $\begin{array}{l}\text { Volume } \\
\left(\mathrm{m}^{3}\right)\end{array}$ & $\begin{array}{l}\text { Mass } \\
(\mathrm{kg})\end{array}$ & $\begin{array}{l}\text { Volume } \\
\left(\mathrm{m}^{3}\right)\end{array}$ & $\begin{array}{l}\text { Mass } \\
(\mathrm{kg})\end{array}$ & $\begin{array}{l}\text { Volume } \\
\left(\mathrm{m}^{3}\right)\end{array}$ & $\begin{array}{c}\text { Mass } \\
(\mathrm{kg})\end{array}$ & $\begin{array}{l}\text { Volume } \\
\left(\mathrm{m}^{3}\right)\end{array}$ & $\begin{array}{c}\text { Mass } \\
(\mathrm{kg})\end{array}$ \\
\hline Cement & 0.12 & 370 & 0.12 & 370 & 0.12 & 370 & 0.12 & 370 & 0.12 & 370 \\
\hline Water & 0.21 & 210 & 0.21 & 210 & 0.21 & 210 & 0.21 & 210 & 0.21 & 210 \\
\hline Coarse aggregate & 0.37 & 985 & 0.37 & 985 & 0.37 & 985 & 0.37 & 985 & 0.37 & 985 \\
\hline Fine aggregates & 0.30 & 802 & 0.29 & 767 & 0.28 & 734 & 0.23 & 610 & 0.19 & 499 \\
\hline PCM & 0 & 0 & 0.01 & 11.8 & 0.03 & 23 & 0.07 & 65.3 & 0.11 & 103.3 \\
\hline Total $\%$ of PCM in mix & 0 & 0 & 1.32 & 0.50 & 2.62 & 1.0 & 7.82 & 3.0 & 12.97 & 5.0 \\
\hline
\end{tabular}




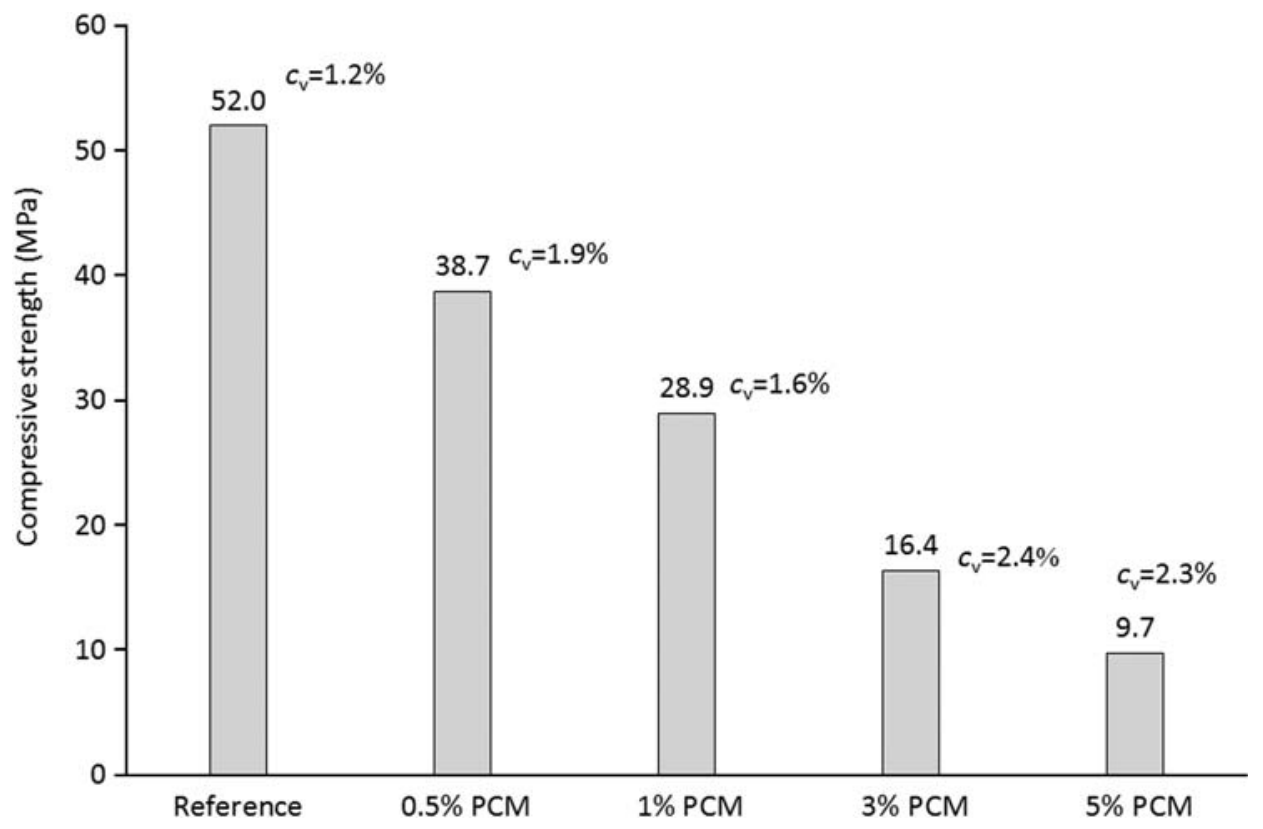

Figure 2. Twenty-eight-day compressive strength of the PCM concrete mixes including the coefficient of variation $\left(c_{\mathrm{v}}\right)$ for each mix.

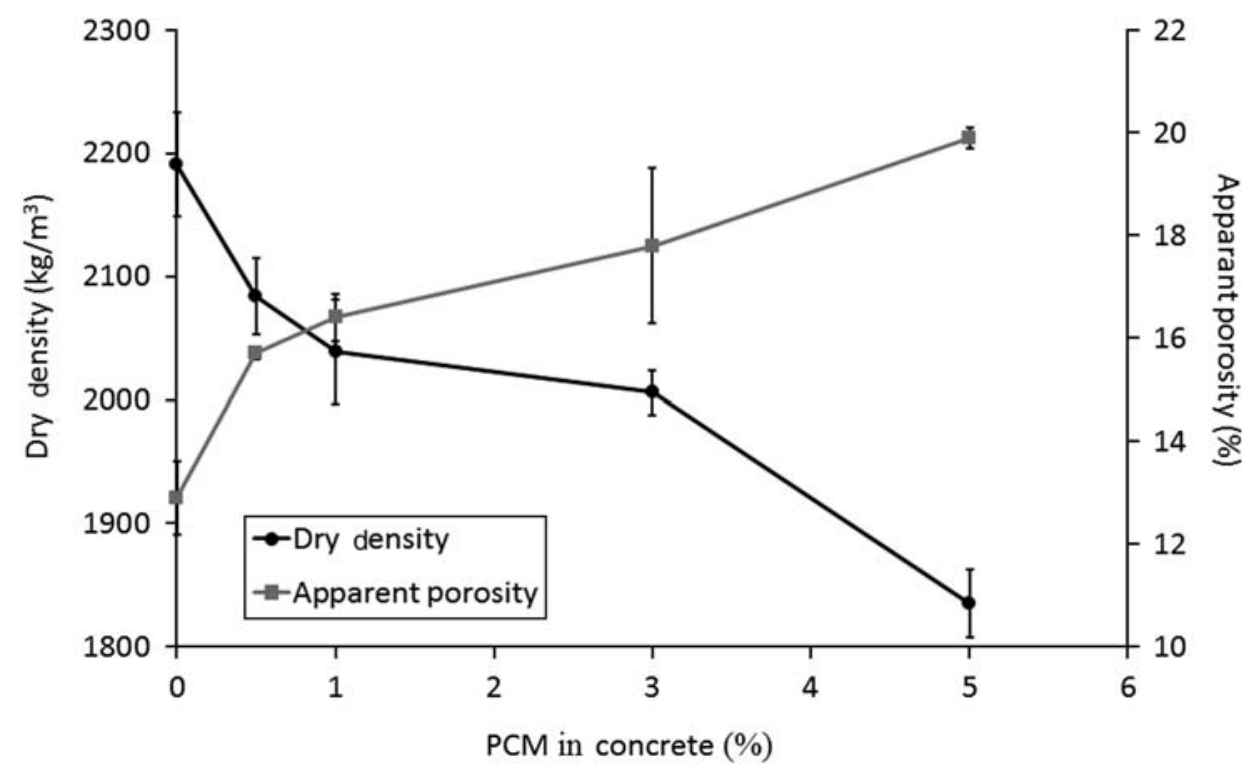

Figure 3. Density and AP of the mixes as a function of the PCM wt\% addition.

mixes can be attributed to the particle density of the PCM $\left(0.90 \mathrm{~kg} / \mathrm{m}^{3}\right)$ compared to the sand $\left(2.64 \mathrm{~kg} / \mathrm{m}^{3}\right)$ as well as an increase in the concrete porosity. It is assumed, at this stage, that the addition of acrylic microencapsulated PCM has an air-entraining effect on concrete mixtures. The ratio of compressive strength loss to AP increase is known to be approximately 5:1 in concrete (Neville 1995, Kumar and Bhattacharjee 2003). However, Figure 4 shows that the relationship between AP and compressive strength of PCM-modified concrete does not follow the expected relationship, suggesting that additional mechanisms contributing to strength loss are likely to be involved (discussed further in Section 5).

Three $100 \times 100 \times 500 \mathrm{~mm}$ prisms were used for the determination of four-point flexural strength for each of the concrete mixes, according to BS EN 12390-5 (2009a). The results are presented in Figure 5 and show that increasing PCM dosage also significantly reduces the flexural strength in concrete. The reduction in flexural strength is $14 \%, 17 \%, 37 \%$ and $45 \%$ for $0.5 \mathrm{wt} \%, 1 \mathrm{wt} \%$, 


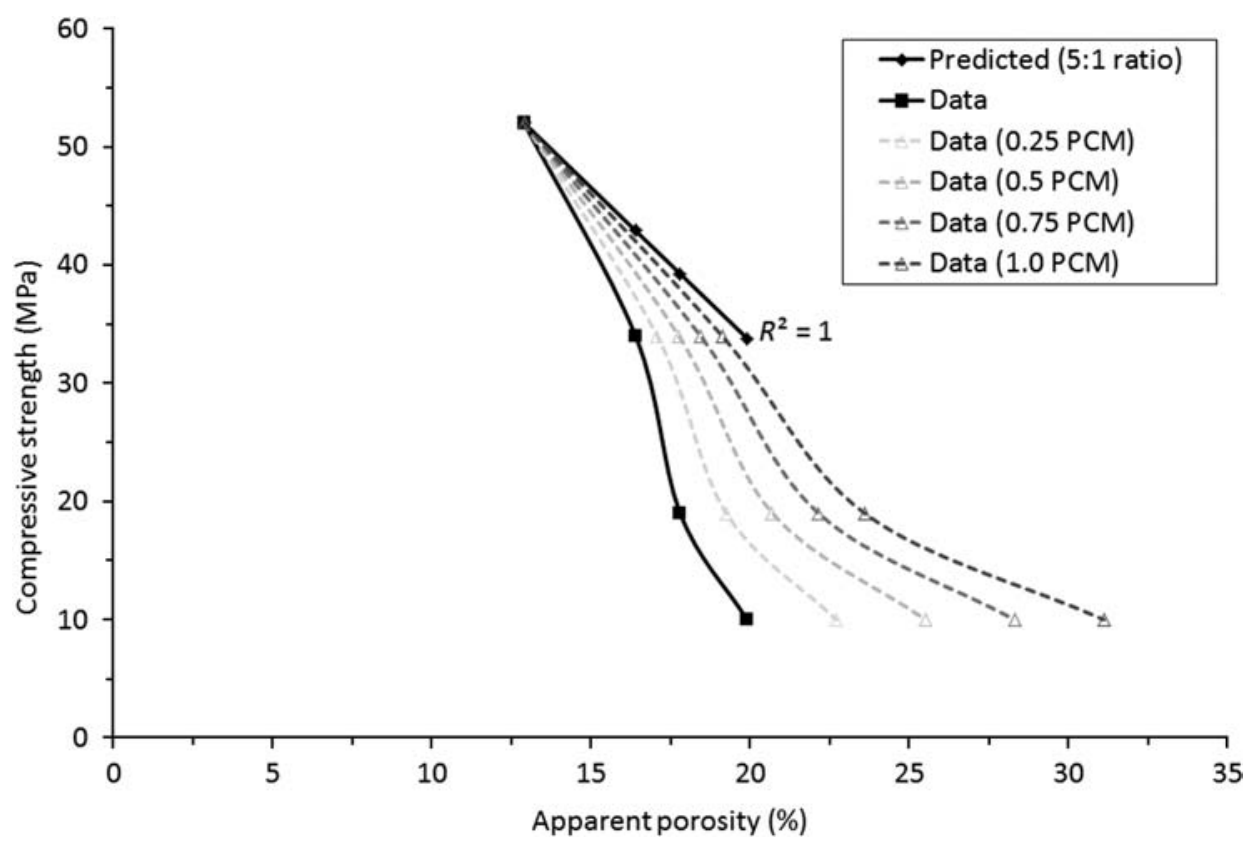

Figure 4. Empirical correlation between compressive strength amendments as a result of AP, with predicted effects of post-loading PCM void formation.

$3 \mathrm{wt} \%$ and $5 \mathrm{wt} \%$ PCM in concrete, respectively. This can partially be attributed to the increase in the AP. The UPV was determined for each prism specimen using a PUNDIT device according to BS 1881-203 (1986). Figure 6 shows that as the PCM dosage increases, the UPV across the length of each prism reduces. This is mostly due to the significant increase in air voids, but may also be partially influenced by the difference in dynamic modulus of the PCM particles.

\section{Thermo-physical properties and thermal storage}

The thermal conductivity of the concrete specimens, following immersion in water $(\lambda *)$ and oven-dried $(\lambda)$ conditions, was experimentally determined using a computer-controlled P.A. Hilton B480 uni-axial heat flow meter apparatus with downward vertical heat flow, which complies with ISO 8301 (ISO 1996). Two slabs with dimensions of $300 \times 300 \mathrm{~mm}$, and a thickness of

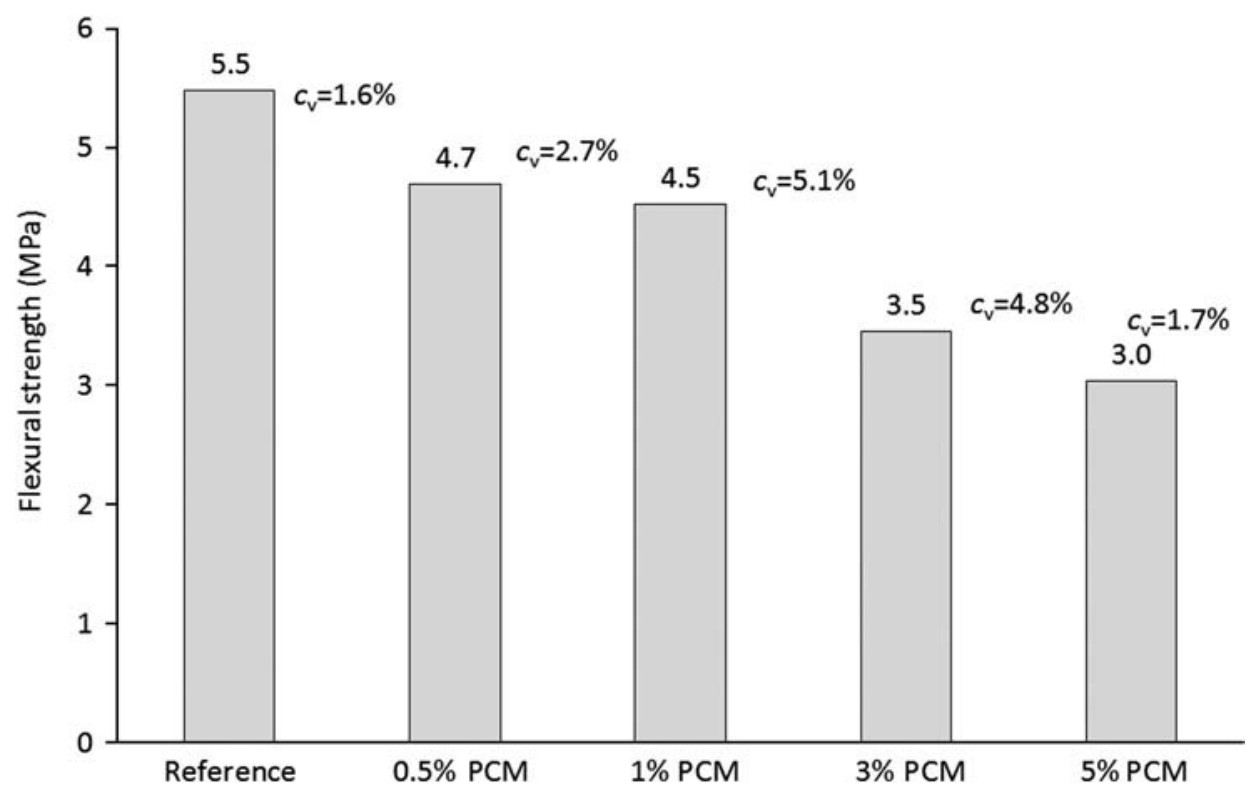

Figure 5. Twenty-eight-day flexural strength of the PCM concrete mixes. 


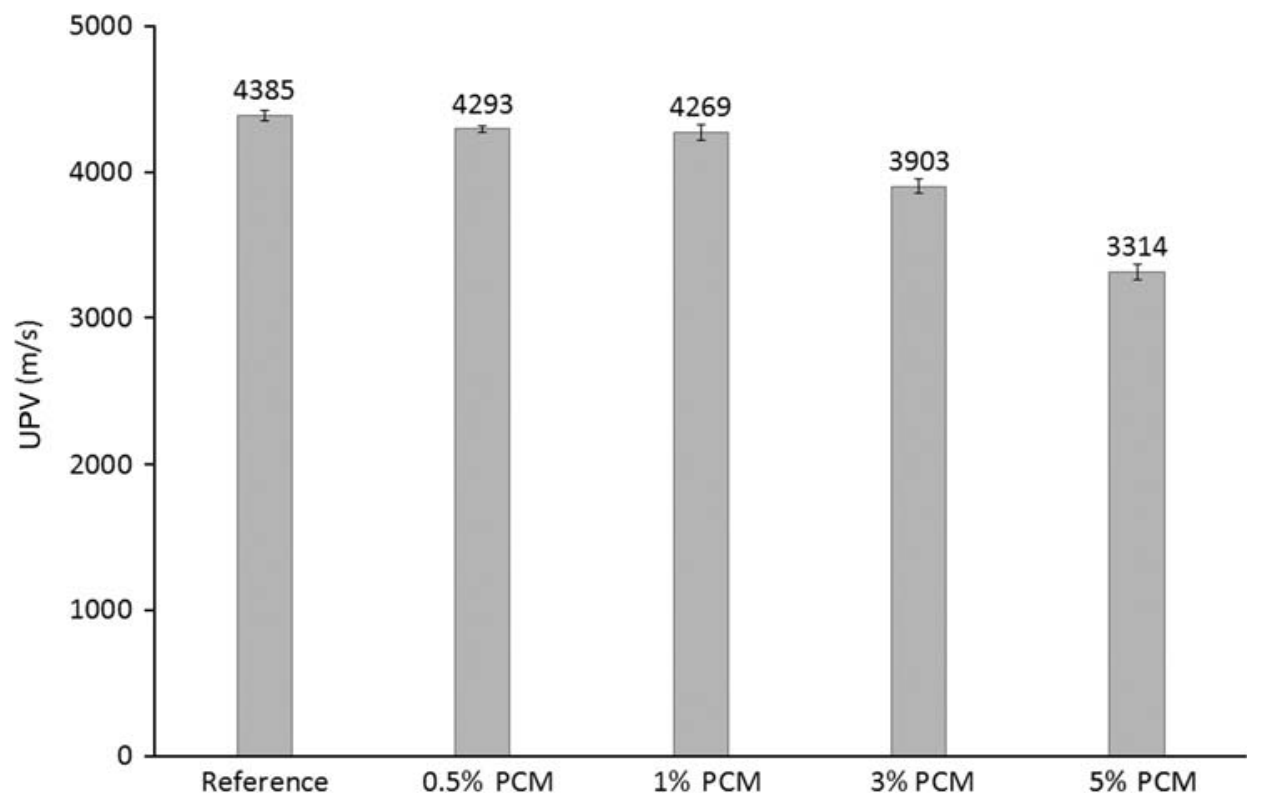

Figure 6. UPV in concrete prisms as a function of the PCM wt\% addition.

approximately $65 \mathrm{~mm}$ were prepared, and then the mean value of three independent readings was obtained for each slab specimen in oven-dried and water-immersed states. For thermal conductivity measurement in wet state, the concrete slabs were removed from the curing tank water at the end of their 28-day curing period and sealed in a vapour-tight envelope to prevent a change in moisture content. The influence of the thin envelope on the thermal conductivity of the slab specimens was found to be negligible when measuring thermal conductivity at a steady-state variance of $\pm 2-3 \%$, as prescribed by ISO 8301 (ISO 1996). In the dry state, all the specimens were oven-dried until the mass changed by less than $0.2 \%$ over $24 \mathrm{~h}$, and then cooled in a desiccator. More detail about the test can be found in previous publications (Keikha et al. 2010). Thermal conductivity values for the concrete mixes tested in this study are presented in Table 2, in which clearly the addition of PCM resulted in a general reduction in thermal conductivity. This can be explained because the increased air-void content, as a result of entrapped air from PCM addition, would decrease inter-particle contact and create air pockets transferring heat by natural convection alone. In addition, the reduction in the volume of sand in concrete can also play a role in the reduction in the thermal conductivity since the sand has a higher conductivity than the PCM particles, although this is highly dependent on the contact resistance between particles. It is also evident that the degree of saturation correlates with a significant increase in the thermal conductivity for each concrete mix that was tested, since the natural convection coefficient within the voids is considerably enhanced when they are filled with liquid as opposed to gas. For these reasons, the rate of increase in thermal conductivity from dry state to water-immersed state also increases in line with the AP of

Table 2. Mean thermo-physical properties of PCM concrete mixes at $25^{\circ} \mathrm{C}$ in dry and wet conditions.

\begin{tabular}{|c|c|c|c|c|c|c|c|c|}
\hline Concrete mixes & $\begin{array}{c}\lambda \\
(\mathrm{W} / \mathrm{m} \mathrm{K})\end{array}$ & $\begin{array}{c}\lambda^{*} \\
(\mathrm{~W} / \mathrm{m} \mathrm{K})\end{array}$ & $\begin{array}{c}c_{\mathrm{p}} \\
(\mathrm{J} / \mathrm{kg} \mathrm{K})\end{array}$ & $\begin{array}{c}c_{\mathrm{p}}^{*} \\
(\mathrm{~J} / \mathrm{kg} \mathrm{K})\end{array}$ & $\begin{array}{c}\alpha \\
\left(\times 10^{-7}\right) \\
\left(\mathrm{m}^{2} / \mathrm{s}\right)^{\mathrm{a}}\end{array}$ & $\begin{array}{c}\alpha^{*} \\
\left(\times 10^{-7}\right) \\
\left(\mathrm{m}^{2} / \mathrm{s}\right)^{\mathrm{b}}\end{array}$ & $\left(\mathrm{J} / \mathrm{s}^{0.5} \mathrm{~m}^{2} \mathrm{~K}\right)^{\mathrm{c}}$ & $\left(\mathrm{J} / \mathrm{s}^{0.5} \mathrm{~m}^{2} \mathrm{~K}\right)^{\mathrm{d}}$ \\
\hline Reference & $1.12 \pm 0.0$ & 1.36 & 963 & 1129 & 5.31 & 5.19 & 1537 & 1887 \\
\hline $0.5 \%$ PCM & $1.07 \pm 0.02$ & 1.31 & 1069 & 1261 & 4.80 & 4.63 & 1544 & 1924 \\
\hline $1 \%$ PCM & $0.94 \pm 0.01$ & 1.18 & 1174 & 1366 & 3.93 & 3.92 & 1500 & 1885 \\
\hline $3 \%$ PCM & $0.86 \pm 0.07$ & 1.09 & 1381 & 1572 & 3.10 & 3.17 & 1544 & 1934 \\
\hline $5 \%$ PCM & $0.71 \pm 0.03$ & 0.95 & 1780 & 1958 & 2.17 & 2.38 & 1523 & 1945 \\
\hline
\end{tabular}

${ }^{\mathrm{a}}$ Data were calculated using $\alpha=\lambda / \rho_{\mathrm{d}} c_{\mathrm{p}}$.

${ }^{\mathrm{b}}$ Data were calculated using $\alpha^{*}=\lambda^{*} / \rho_{\mathrm{ssd}} c_{\mathrm{p}}^{*}$

${ }^{\mathrm{c}}$ Data were calculated using $\beta=\sqrt{\left(\lambda \rho_{\mathrm{d}} c_{\mathrm{p}}\right)}$.

${ }^{\mathrm{d}}$ Data were calculated using $\beta^{*}=\sqrt{\left(\lambda^{*} \rho_{\mathrm{ssd}} c_{\mathrm{p}}^{*}\right)}$. 
the material, as can be seen in Table 2 and Figure 3. In practice, an increase in thermal resistance (reduced $\lambda$ ) could lead to energy savings in construction materials applications. The thermal diffusivity in dry state $(\alpha)$ and wet state $\left(\alpha^{*}\right)$ has been calculated and presented in Table 2 , along with the thermal effusivity in dry state $(\beta)$ and wet state $(\beta *)$. The thermal diffusivity reduces as wt\% of added PCM increases, and expresses the rate of temperature change (in $\mathrm{m}^{2} / \mathrm{s}$ ) when a material is exposed to a fluctuating thermal environment. The reduction in thermal diffusivity of PCM-modified concrete is due to the reduction in thermal conductivity as well as the increase in specific heat capacity. Thermal effusivity (also known as the coefficient of heat storage) is a measure of the material's ability to exchange heat with its surroundings, and this fluctuates as wt\% of added PCM increases. This occurs when the decrease in thermal conductivity is partially offset by increases in heat capacity.

The mean heat capacity of each concrete mix was calculated as the sum of the specific heat capacities of the constituent parts weighted by their relative mass proportions. It was assumed that air in the voids had a negligible contribution to the heat capacity of the total concrete since it has a density of approximately $1.205 \mathrm{~kg} / \mathrm{m}^{3}$ at ambient temperatures and so was neglected. A TA Instruments Q10 differential scanning calorimeter coupled with mechanical cooling was used to determine the specific heat capacity of the aggregates, hardened cement paste (HCP) and PCM powder. Testing was carried out on samples of $\sim 10 \mathrm{mg}$ for the PCM and $\sim 30 \mathrm{mg}$ for the other constituents. Samples were equilibrated at $-15^{\circ} \mathrm{C}$ and maintained isothermally for $10 \mathrm{~min}$ before being ramped to $60^{\circ} \mathrm{C}$ at a rate of $1^{\circ} \mathrm{C} / \mathrm{min}$. Optimum ramp rate (i.e. $1^{\circ} \mathrm{C} / \mathrm{min}$ ) was found by iteration starting at $5^{\circ} \mathrm{C} / \mathrm{min}$ and gradually decreasing until the curve acquired the correct shape (i.e. peaks in the middle and not to the right). The samples were then held isothermally at $60^{\circ} \mathrm{C}$ for $10 \mathrm{~min}$ to complete the test run. The empty aluminium sample crucibles (TA Instruments, Germany, Eschborn) were calibrated using the same ramp procedure to achieve a baseline and again using a certified reference specimen of pure sapphire $\left(\alpha-\mathrm{Al}_{2} \mathrm{O}_{3}\right)$. The purge gas used was argon at a flow rate of $50 \mathrm{ml} / \mathrm{min}$. The specific heat capacity of concrete at $25^{\circ} \mathrm{C}$ in both the dry $\left(c_{\mathrm{p}}\right)$ and wet $\left(c_{\mathrm{p}}^{*}\right)$ states is calculated from Equations (2) and (3), and is presented in Table 2 .

$$
c_{\mathrm{p}}=\left[\frac{1}{w_{\text {total }}[w]_{\mathrm{HCP}} c_{\mathrm{HCP}}}+w_{\mathrm{CA}} c_{\mathrm{CA}}+w_{\mathrm{FA}} c_{\mathrm{FA}}+w_{\mathrm{PCM}} c_{\mathrm{PCM}}\right],
$$

$$
c_{\mathrm{p}}^{*}=c_{\mathrm{p}}+\frac{\mathrm{AP} \times \rho_{\text {water }}}{w_{\text {total }}} \times c_{\text {water }} .
$$

Figure 7 shows the dry-state mean specific heat capacity $\left(c_{\mathrm{p}}\right)$ of concrete across a temperature range of $-10^{\circ} \mathrm{C}$ to $50^{\circ} \mathrm{C}$. PCMs are normally defined by a mean melting temperature, in this case $T_{\text {melt }}=26^{\circ} \mathrm{C}$. Due to the level of purity and varying particle diameters, phase change typically occurs across a narrow temperature range close to the mean value, which is approximately $22-30^{\circ} \mathrm{C}$

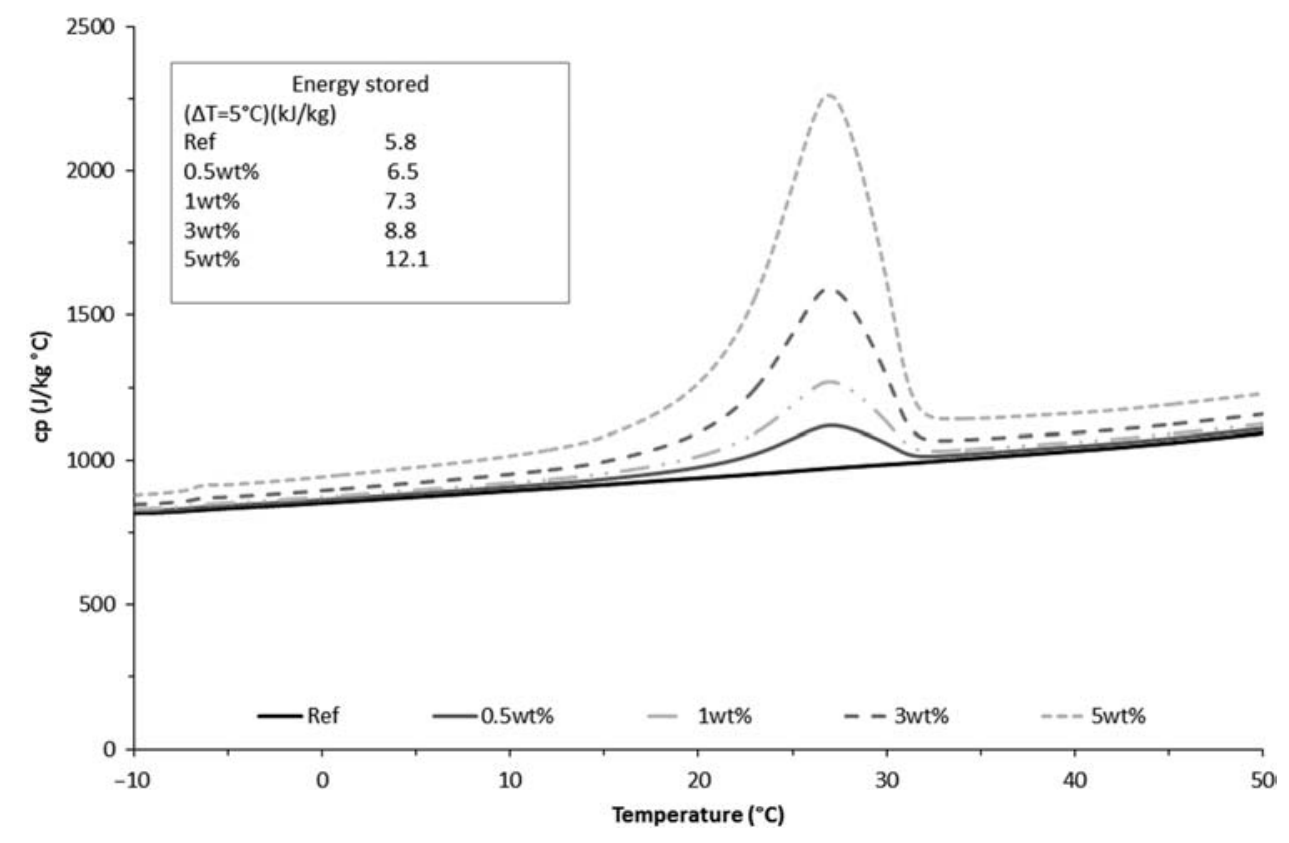

Figure 7. Dry-state specific heat capacity and thermal storage capacity of the PCM concrete mixes as a function of temperature. 
(see Figure 7). Previous studies have shown that by using smaller heating/cooling rates or smaller sample mass in differential scanning calorimetry, the observed melting range can be reduced (Mehling and Cabeza 2008). Clearly, even a relatively small addition of PCM results in a significant and temperature-critical increase in heat capacity for modified concrete materials. The quantity of latent energy stored in the PCM is equal to the area under the peak that surrounds the mean melting temperature, the values for which are provided in Figure 7 assuming a $\Delta T$ of $5^{\circ} \mathrm{C}$. In order to store $11.1 \mathrm{KJ} / \mathrm{kg}$ as sensible heat, for example, by increasing concrete temperature (with no PCM), a $\Delta T$ of $>13^{\circ} \mathrm{C}$ is needed, while the same amount of energy can be stored in the $5 \%$ PCM mix with a $\Delta T$ of only $5^{\circ} \mathrm{C}$.

\section{Microstructural characterisation of PCM- modified concrete}

The microstructure of the dry PCM and the PCM-modified concrete were characterised using a Philips XL-30 field emission gun environmental SEM equipped with Oxford Instruments Inca model EDS, Abingdon, Oxfordshire, United Kingdom. Micrographs were recorded under high vacuum mode using an Everhart-Thornley type SE detector and a backscattered electron (BSE) detector supplied by K.E. Developments. Elemental mapping was carried out using an EDS spectral analysis at $113 \mathrm{eV}$ resolution.

The PCM samples were prepared by depositing $<5 \mathrm{mg}$ of the dry powder onto an adhesive carbon tab attached to an $A l$ stub, and by removing the surplus by compressed air followed by Pt sputter coating. A second stub sample was produced in exactly the same way, but the PCM particles were artificially damaged by placing a thin sheet of mica over the powder and by applying a small amount of pressure using a 7-mm round-nosed spatula. Previous researchers have hypothesised that loose, ejected wax from damaged/leaking PCM particles could be responsible for the measured reductions in compressive strength (Hunger et al. 2009). It is unclear whether this would principally occur during the mixing phase, and hence, the wax would become entangled with the hardening cement paste perhaps causing localised voids and crack initiation points, or disrupting the interfacial transition zone (ITZ) by coating aggregate surfaces. Alternatively, the PCM particles could remain intact during mixing and the wax only leaks under loading leading to lubrication and/or expedition of crack growth.

Figure 8 shows that the particles are spherical with an amorphous appearance. The outer polymeric shell was measured to be approximately $200 \mathrm{~nm}$ thick and comprises gelled acrylic beads surrounding the platy paraffin core. The rim of three opened PCM particles was imaged using the SE detector at $10 \mathrm{kV}$, spot size 1 . Five shell thickness measurements were taken for each particle along the rim, and the approximate value was recorded as $200 \mathrm{~nm}$. The shell thickness may vary slightly along the perimeter, and for a precise assessment of mean value and standard deviation a statistical study would be required. However, considering the nature of the investigations in this study this was deemed unnecessary and the shell was simply

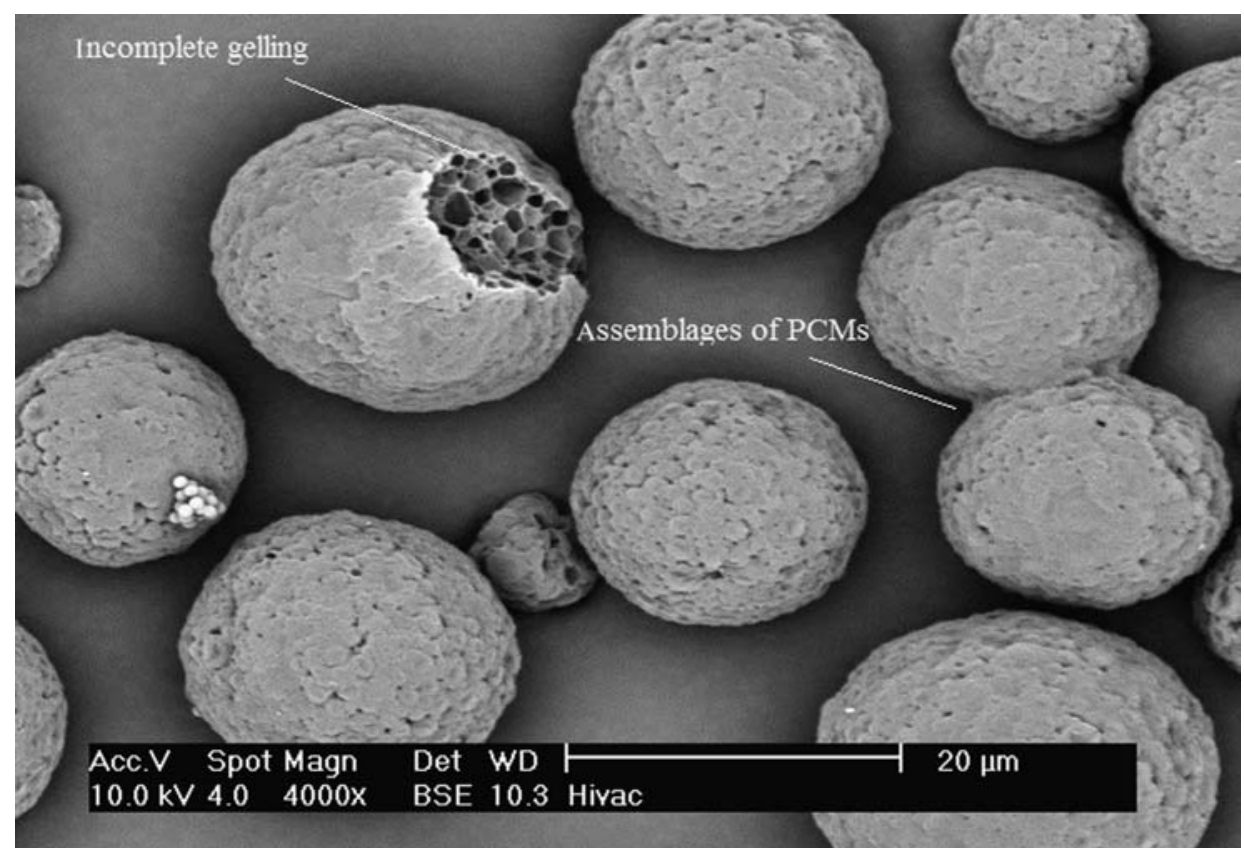

Figure 8. Spherical PCM particles showing an amorphous surface comprising gelled acrylic beads surrounding the platy paraffin core. 
very thin and of the order $200 \mathrm{~nm}$ thick. In addition, Figure 8 shows that there is some evidence of incomplete gelling, and also some inter-particle gelling resulting in assemblages which when fractured expose the paraffin core. As anticipated, EDS analysis revealed the elemental composition to be principally carbon and oxygen (acrylic and paraffin are hydrocarbons) with no evidence of significant contamination. This approach was designed to enable the authors to reliably locate and identify both intact and damaged PCM particles (as well as any ejected wax) within the highly varying textures of hardened concrete.

Concrete SEM samples were prepared as a small fragment prized away from a failed $500 \mathrm{~mm}$ prism of the $5 \mathrm{wt} \%$ PCM-modified concrete. The imaged surface was an untouched fracture surface from one of the central cracks running along the prism. The fragments were mounted on an Al stub with carbon cement, Pt sputter coated and imaged in the high vacuum SEM mode. Evidence of PCM particles was found to be well distributed throughout the hardened microstructure, and it was apparent either in the form of hemispherical voids (characteristic of PCM particle shape and surface texture) from where PCM particles had been embedded during curing then later pulled out (see Figure 9), or in the form of damaged or collapsed PCM particles still occupying the void (see Figure 10). No direct evidence was found for damage to PCM particles that had arisen during mixing or compaction of fresh concrete, i.e. split or crushed particles surrounded/embedded by the hardened concrete. Instead, the presence of spherical voids (with or without a PCM particle inside), as shown by the example of such a void perimeter in Figure 11, suggests that damage and subsequent ejection of the wax occur post-curing.

The damaged PCM particles appear to have failed by bursting (see Figure 10), which could either occur postloading or perhaps from high temperature late-stage heat of hydration. The latter is perhaps unlikely since the PCM particles used in this study can withstand temperatures in excess of $\sim 100^{\circ} \mathrm{C}$ as stated in the product datasheet. In these observations, the outer shell was ruptured in several places and the wax core was ejected, resulting in the creation of a spherical void and the remnants of the deflated acrylic PCM shell. Some evidence of paraffin wax was observed at several points along the sample surface, and it is reasonable to assume that, since the sample surface was an undisturbed failure plane, the ejected wax from compressed PCM particles escapes into cracks as they propagate perhaps contributing to lubrication. The example of selected elemental mapping in Figure 12 shows a typical failed PCM particle, identified with high C concentrations, and adjacent cement microstructure with high $\mathrm{Ca}$ and $\mathrm{Si}$ concentrations. ITZ failure as a result of particle shrinkage by wax ejection is clearly visible. There is some evidence of wax dispersion across the adjacent sample surface.

Figure 13 shows a selection of hemispherical voids, some of which (e.g. top right) appear to have been created as a result of PCM particle pre-curing embedment followed by post-loading pull-out. Others (e.g. top left and bottom left) appear to be air entrapment voids, which may occur as a result of PCM addition during mixing since

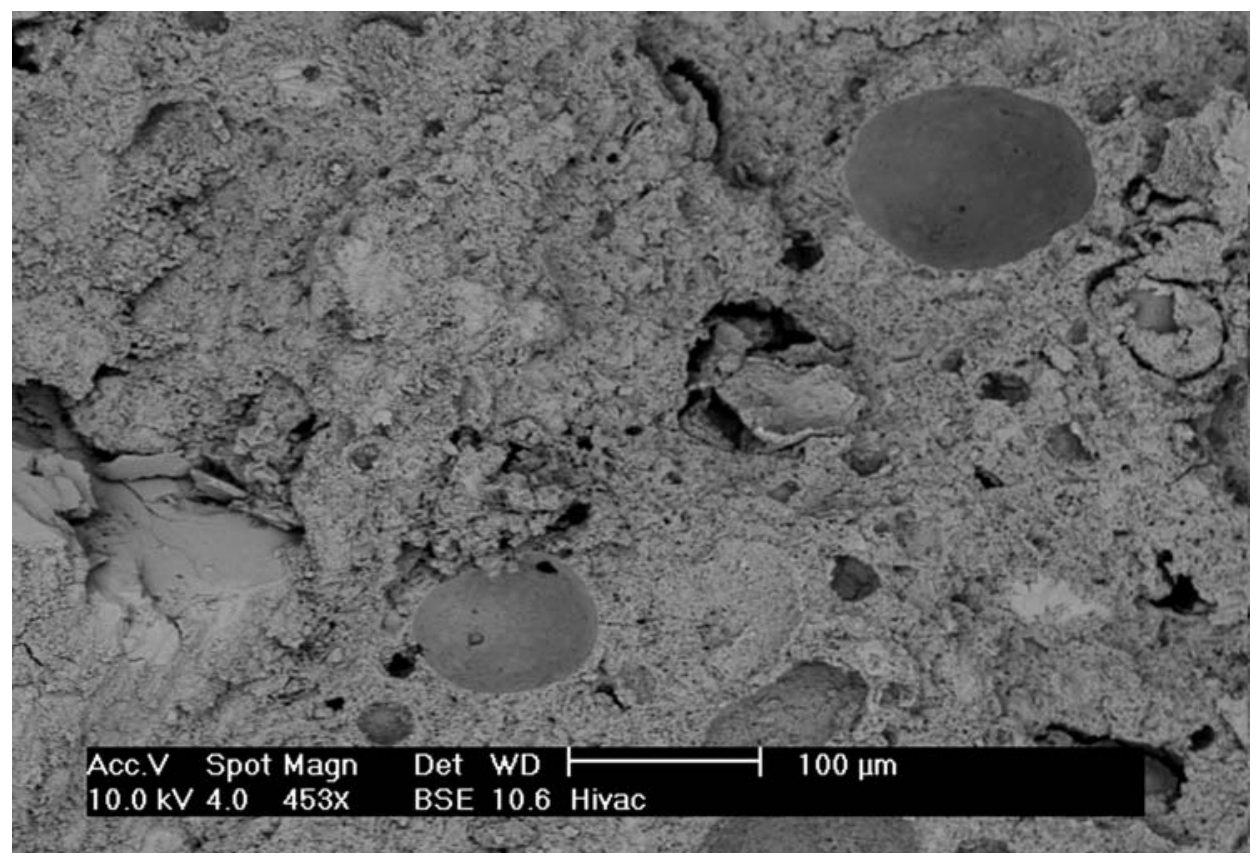

Figure 9. SEM micrograph of concrete fracture surface showing hemispherical voids using BSE detector. 


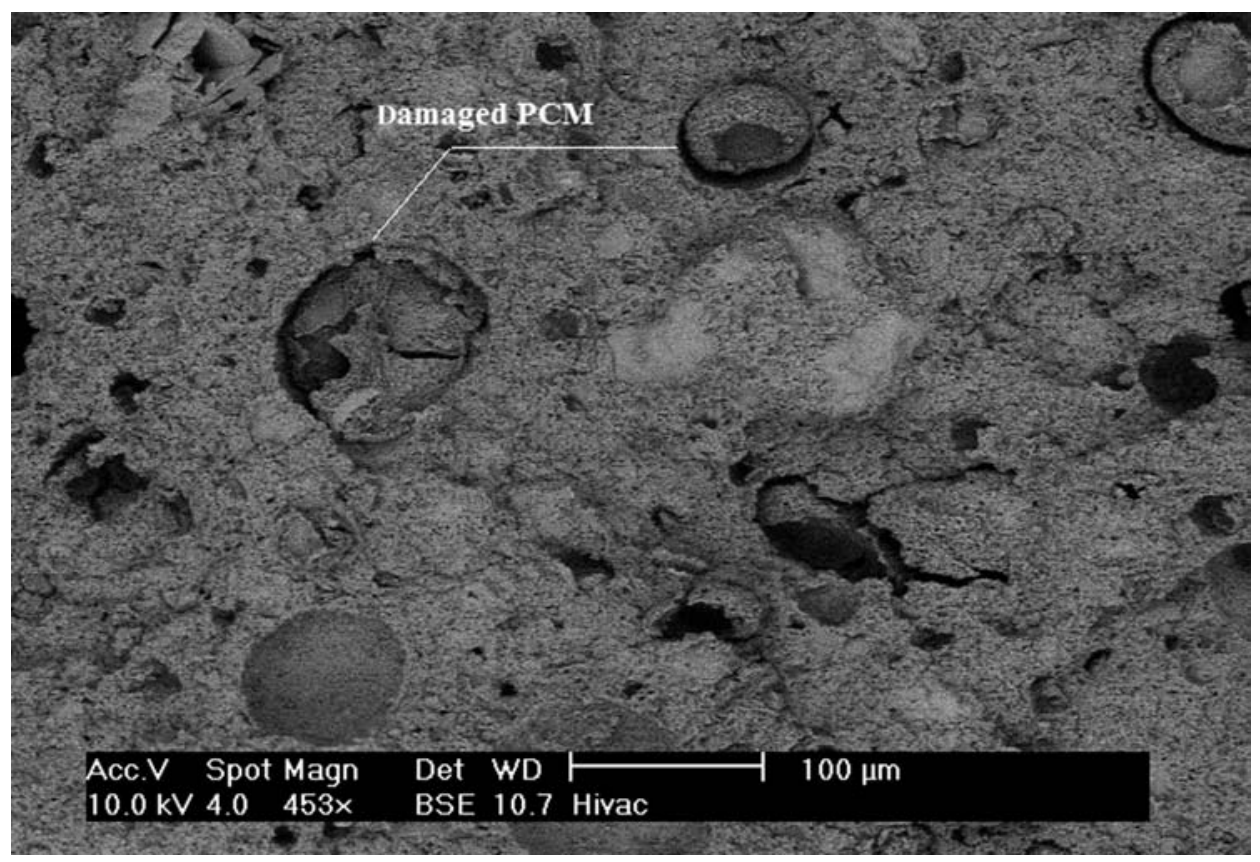

Figure 10. SEM micrograph (using BSE detector) of concrete fracture surface showing damaged or collapsed PCM particles still occupying their original void.

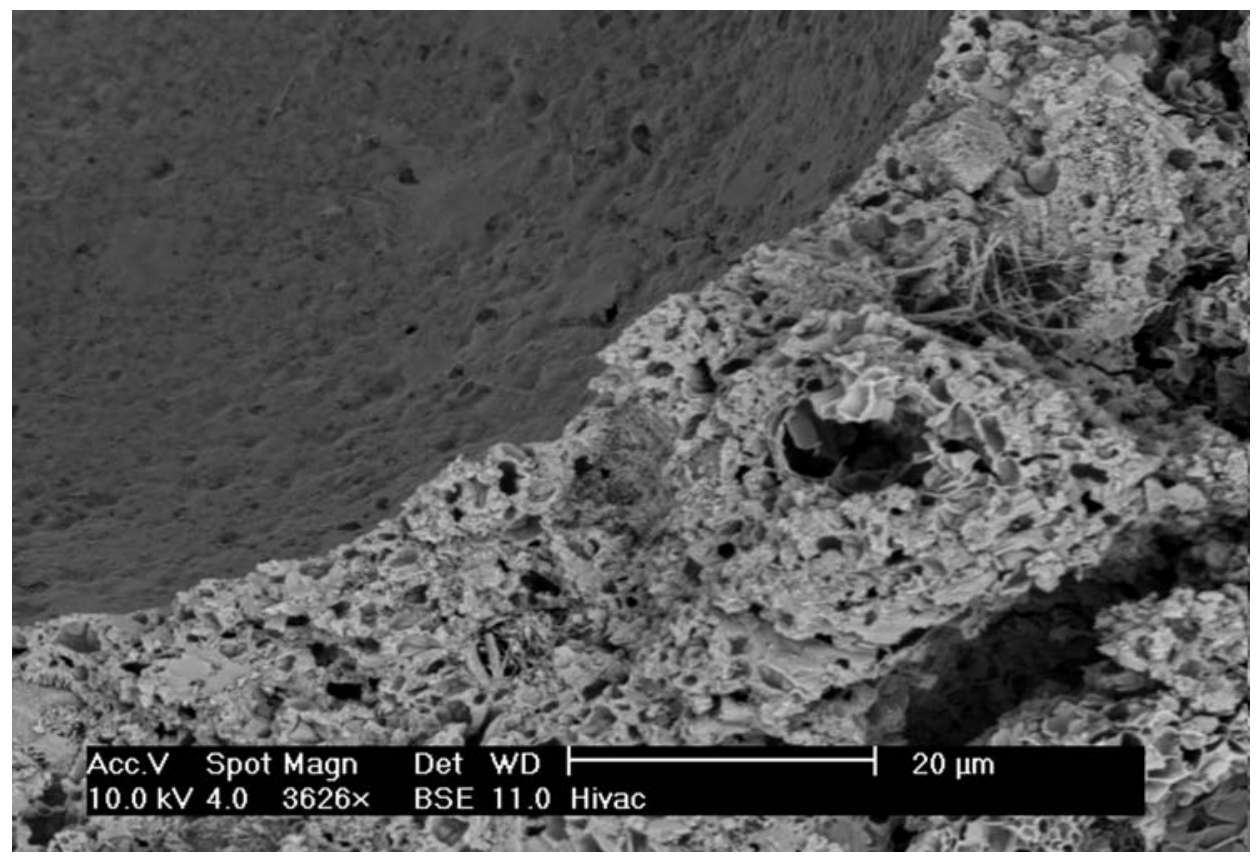

Figure 11. SEM micrograph (using BSE detector) of the perimeter rim of a void that appears to have been formed by a PCM particle.

(i) no air-entraining admixture was used here and (ii) the measured AP increased with PCM addition (see Figure 3). This enables the growth of calcium hydroxide $\left(\mathrm{CaOH}_{2}\right)$ crystals inside the void, most likely from adjacent di- and tri-calcium silicate hydration reactions in the HCP. Some pieces of evidence of post-loading cracks are clearly evident across these voids propagating into the adjacent microstructure. As mentioned in Section 3, the relationship between AP and compressive strength of PCMmodified concrete does not follow the expected relationship suggesting that additional mechanisms contributing to strength loss are likely to be involved (see Figure 4). 

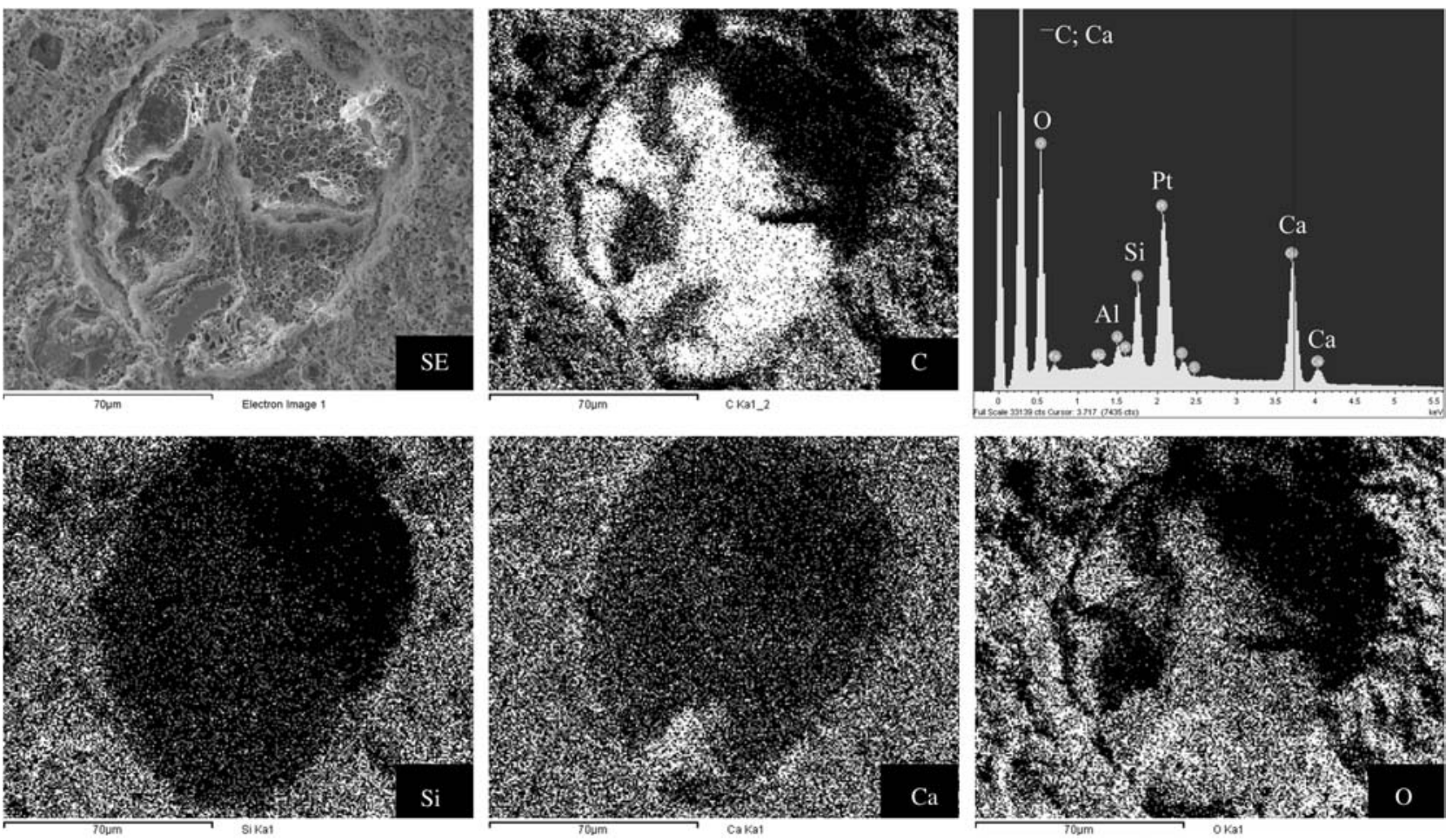

Figure 12. Elemental mapping using EDS spectral analysis shows a typical failed PCM particle, identified with regions of high carbon concentration.

Figure 4 shows a prediction of porosity for different cases in which 25\%,50\%, 75\% and 100\% of PCM capsules burst under loading and hence increase the AP of the concrete. Figure 4 clearly shows the changes to porosity, due to bursting of PCMs, gives a much better fit and approaches the expected porosity/strength prediction.

\section{Numerical analysis of PCM-modified concrete pavement behaviour}

In order to simulate the relative effects of PCM addition on surface temperature of concrete slabs, a 1D finite difference transient heat transport model [previously validated (Keikha et al. 2010)] was used. The model is accurate to within $2^{\circ} \mathrm{C}$ variation, and was found to give results as least as good as other similar models (Yavuzturk et al. 2005, Gui et al. 2007). The model predicts slab temperature at various different depths in response to the climatic variables period and was modified to include the temperature-critical enthalpy of phase transition for PCMmodified materials. Refer to Hu and Argyropoulos (1996) for a review of the major mathematical modelling techniques for solidification and melting. In this study, the 'apparent heat capacity method' was incorporated within the numerical model, which accounts for the latent heat capacity of the PCM by adding a heat capacity function to the narrow temperature range over which phase change occurs. To validate the modified model, two concrete discs ( $100 \mathrm{~mm}$ diameter and $20 \mathrm{~mm}$ thick) were prepared: one containing $0 \mathrm{wt} \% \mathrm{PCM}$ and the other with $5 \mathrm{wt} \%$ PCM. Both discs were instrumented by attaching two T-type (copper/constantan) thermocouples to their surfaces. The concrete specimens were insulated by encasing them in a rigid board of expanded urethane, leaving only one face exposed. The exposed surface was covered in aluminium foil to ensure that both specimens had the same surface absorptivity and that changes in surface temperatures were not affected by albedo. The specimens were pre-conditioned at a dry bulb air temperature of $5 \pm 0.5^{\circ} \mathrm{C}$ before being placed under a halogen lamp array. Solar intensity was measured using a pyranometer (Kipp \& Zonen CMP3, 125 Wilbur Place, Bohemia, NY 11716, USA) and recorded at 10-s intervals using a datalogger (Data Taker DT800, Royston, United Kingdom), along with concrete surface temperatures and ambient air temperature. Figure 14 shows the experimental and predicted data for mean surface temperature evolution for the two concrete samples as a function of time. The influence of the PCM can be clearly observed, producing a shouldered peak that corresponds to the median melting temperature $\left(\sim 26^{\circ} \mathrm{C}\right)$. The temporary increase in heat capacity causes a surface temperature reduction of up to $4^{\circ} \mathrm{C}$ throughout the melting temperature range (approximately $22-30^{\circ} \mathrm{C}$ ). Figure 14 shows the predicted surface 

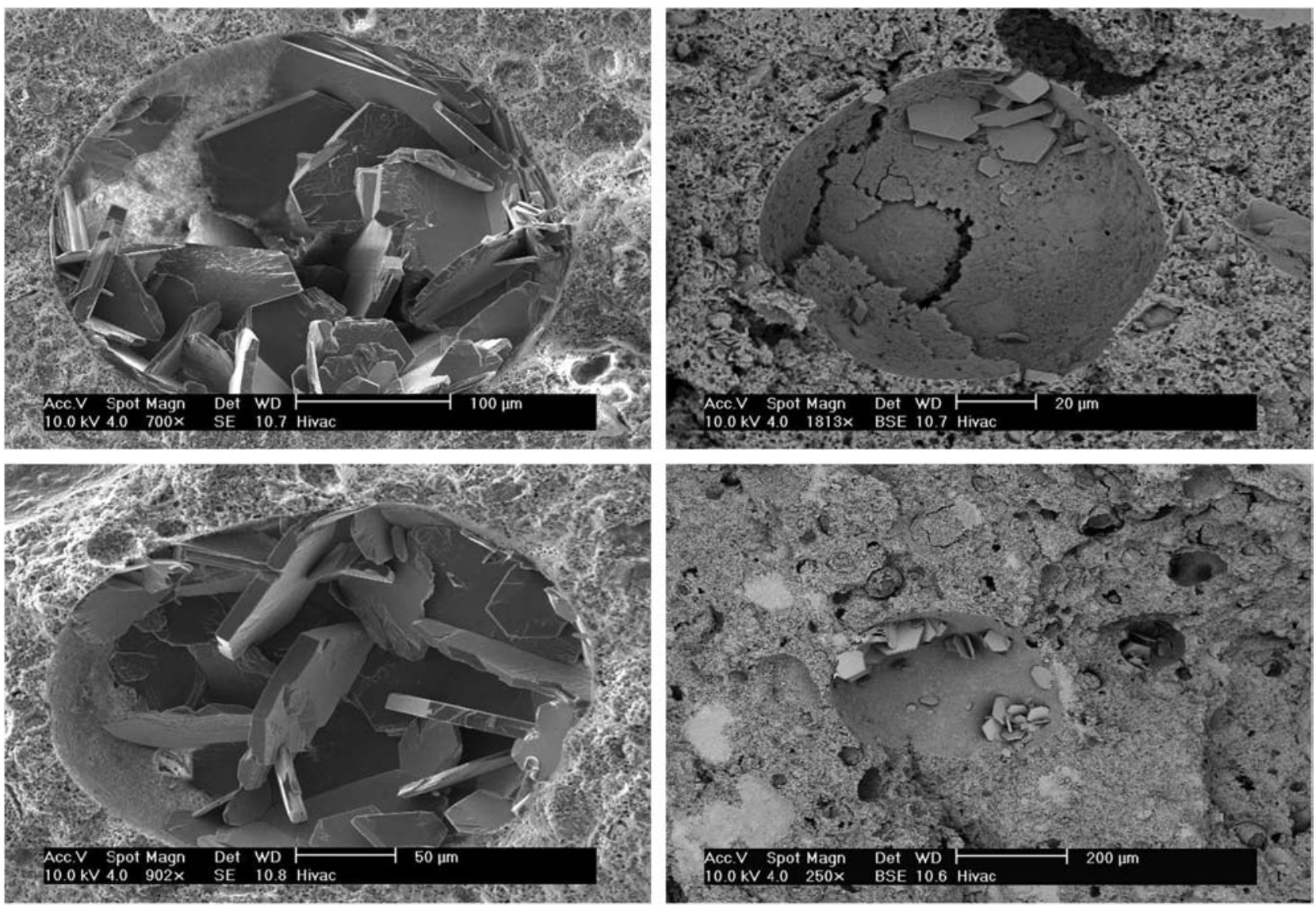

Figure 13. SEM micrographs showing a selection of representative hemispherical voids containing calcium hydroxide crystals.

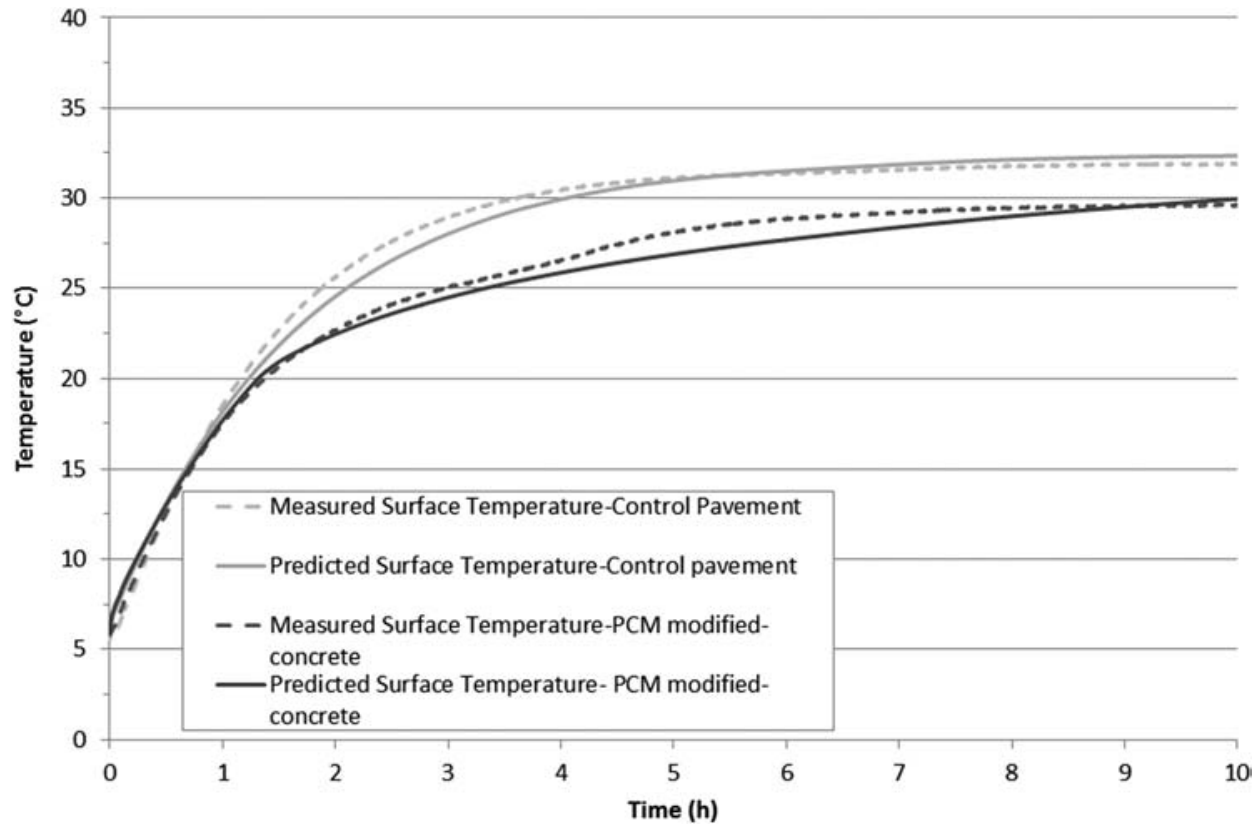

Figure 14. Measured and predicted surface temperature for control concrete and $5 \%$ PCM-modified concrete, including the $\pm 2{ }^{\circ} \mathrm{C}$ accuracy. 


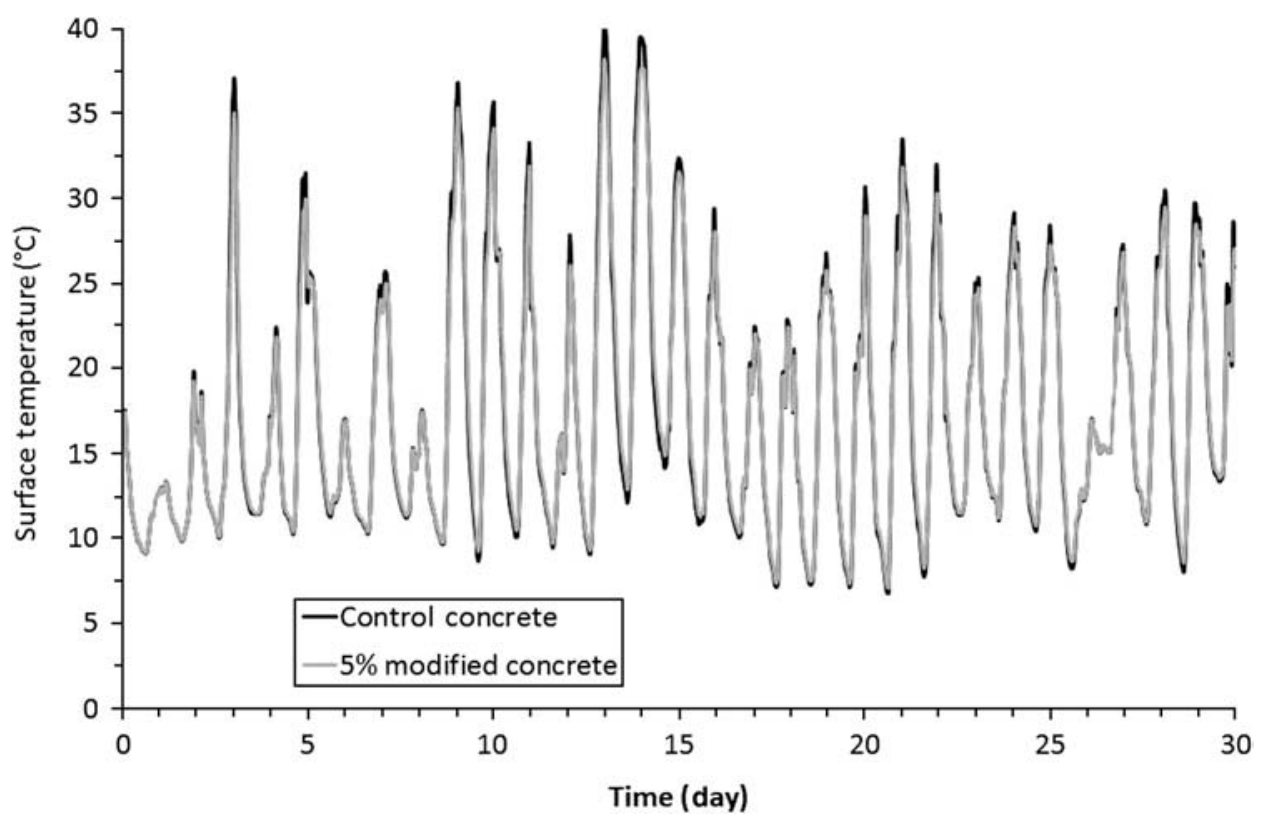

Figure 15. Predicted surface temperature for a concrete pavement comprising the control mix and 5\% PCM-modified concrete.

temperature for control concrete and $5 \mathrm{wt} \%$ PCMmodified concrete, determined using the numerical model and including the $\pm 2^{\circ} \mathrm{C}$ accuracy.

Further numerical simulation was conducted for a typical pavement cross section of a 200-mm concrete surface layer, 100-mm crushed aggregate base layer and compacted soil subgrade (American Concrete Institute 2008). The climatic data were collected from the University of Nottingham weather station at Sutton Bonington, Leicestershire, UK $\left(52.58^{\circ} \mathrm{N}, 1.38^{\circ} \mathrm{W}\right)$; between 1 June 2008 and 1 July 2008 at day time, conventional pavement surface temperature can be expected to rise above $T_{\text {melt }}$ but fall beneath this value at night. Comparative surface temperature predictions were made for pavements using a surface layer comprising the control mix and $5 \mathrm{wt} \%$ PCM-modified concrete. The $5 \mathrm{wt} \%$ PCM-modified concrete was selected for comparison in order to show the largest effect on the surface temperature variations. The PCM was assumed to have properties of $T_{\text {melt }}=26^{\circ} \mathrm{C}$ and $H_{\text {melt }}=160 \mathrm{~kJ} / \mathrm{K}$ as used in this study; however, various PCMs are readily available with a wide range of transition temperatures (Mehling and Cabeza 2008). From Figure 15, it can be clearly observed that as the pavement surface temperature approaches $T_{\text {melt }}$, the rate of temperature change decreases. The maximum concrete surface layer temperature can be reduced by approximately $3.5^{\circ} \mathrm{C}$ under these climatic conditions. Reduction in summer surface temperature could theoretically reduce shrinkage and thermal stresses (e.g. curling, warping and so on) in concrete pavements thus extending its service life. However, PCM-modified concrete could be applied to other applications such as concrete roofs or other precast concrete panels. Although this was not studied in this investigation, characterisation of thermal expansion coefficients in PCM-modified concrete combined with finite element modelling could allow detailed predictions relating to warping reduction as a result of the temperature profile modifications resulting from PCM inclusion. In addition, it may also be interesting to consider the compromise between any additional benefits of PCM-modified concrete and the cost associated with these materials in a future study.

\section{Conclusions}

This paper presented the results of thermo-physical, mechanical and microstructural characterisation of concrete modified with $0.5 \mathrm{wt} \%, 1 \mathrm{wt} \%, 3 \mathrm{wt} \%$ and $5 \mathrm{wt} \%$ microencapsulated PCM. Within the limits of the PCM type, melting temperature, enthalpy and concrete mix design, the following conclusions can be drawn on the basis of the results and analysis presented in this study.

(1) The loss of compressive strength is significant and the percentage reduction in strength is approximately $25 \%, 45 \%, 70 \%$ and $80 \%$ for $0.5 \mathrm{wt} \%, 1 \mathrm{wt} \%, 3 \mathrm{wt} \%$ and $5 \mathrm{wt} \% \mathrm{PCM}$ addition, respectively.

(2) Increasing PCM dosage reduces the flexural strength in concrete and the reduction is $14 \%, 17 \%, 37 \%$ and $45 \%$ for $0.5 \mathrm{wt} \%, 1 \mathrm{wt} \%, 3 \mathrm{wt} \%$ and $5 \mathrm{wt} \%$ PCM addition, respectively.

(3) Regarding the thermo-physical properties of PCMmodified concrete, the experimental results showed a reduction in thermal conductivity and thermal 
diffusivity occurred with increasing amounts of PCM addition. These are chiefly due to increased concrete porosity from entrapped air caused by the PCM, as well as changes to the specific heat capacity.

(4) The volumetric heat capacity of PCM-modified concrete increased significantly across the PCM melting temperature range. A $\Delta T$ of $>13^{\circ} \mathrm{C}$ is needed to store $11.1 \mathrm{~kJ} / \mathrm{kg}$ energy in plain concrete, for example, while the same amount of energy can be stored in the $5 \mathrm{wt} \%$ PCM-modified mix with a $\Delta T$ of only $5^{\circ} \mathrm{C}$.

(5) Microstructural analysis showed that PCMs appear to remain intact during mixing and are well bonded with cement with little evidence of perimeter voids at the ITZ. In addition, there was no evidence of split or crushed PCMs encased within the hardened concrete, which suggests that damage to PCM particles occurs post-curing/loading.

(6) PCM particles appear to fail by bursting under loading, creating hemispherical voids either as the result of pull-out or still containing the remnants of the deflated acrylic PCM shell. Bursting of PCM particles will increase the AP beyond the values determined by immersion of concrete, assuming that they are intact post-curing but pre-loading. This is supported by predictions of increased \%AP versus measured decrease in mechanical strength, and also by microstructural observations of the hemispherical PCM voids acting as crack initiation points. Future research will focus on ways to reduce or eliminate the reductions in mechanical strength loss by developing microencapsulated PCM particles with strong outer shells that will resist bursting under load.

(7) The result of finite difference numerical simulation showed that, by adding $5 \mathrm{wt} \%$ microencapsulated PCM, the concrete surface layer temperature can be reduced by approximately $3.5^{\circ} \mathrm{C}$.

\section{Acknowledgements}

The authors wish to acknowledge the financial support of this research by the Engineering and Physical Sciences Research Council (EPSRC) and East Midlands Airport.

\section{References}

Baetens, R., Jelle, B.P., and Gustavsen, A., 2010. Phase change materials for building applications: a state-of-the-art review. Energy and Buildings, 42 (9), 1361-1368.

Bayés-García, L., et al., 2010. Phase change materials (PCM) microcapsules with different shell compositions: preparation, characterization and thermal stability. Solar Energy Materials and Solar Cells, 94 (7), 1235-1240.

Bentz, D.P. and Turpin, R., 2007. Potential applications of phase change materials in concrete technology. Cement and Concrete Composites, 29 (7), 527-532.
British Standards Institution, 1986. Testing concrete, recommendation for measurment of velocity of ultrasonic pulses in concrete. BS 1881-203.

British Standards Institution, 2008. Aggregates for concrete. BS en 12620:2002 + a1.

British Standards Institution, 2009a. Testing hardened concrete, part 5: flexural strength of test specimens. BS en 12390-5.

British Standards Institution, 2009b. Testing hardened concrete, part 7: density of hardened concrete. BS en 12390-7.

British Standards Institution, 2009c. Testing hardened concrete, part 3: compressive strength of test specimens. BS EN 12390-3.

Cabeza, L.F., et al., 2007. Use of microencapsulated PCM in concrete walls for energy savings. Energy and Buildings, 39 (2), 113-119.

Castell, A., et al., 2010. Experimental study of using PCM in brick constructive solutions for passive cooling. Energy and Buildings, 42 (4), 534-540.

Entrop, A.G., Brouwers, H.J.H., and Reinders, A.H.M.E., 2011. Experimental research on the use of micro-encapsulated phase change materials to store solar energy in concrete floors and to save energy in dutch houses. Solar Energy, 85 (5), 1007-1020.

Gui, J., et al., 2007. Impact of pavement thermophysical properties on surface temperatures. Journal of Materials in Civil Engineering, 19 (8), 683-690.

$\mathrm{Hu}, \mathrm{H}$. and Argyropoulos, S.A., 1996. Mathematical modelling of solidification and melting: a review. Modelling and Simulation in Materials Science and Engineering, 4 (4), 371-396.

Hunger, M., et al., 2009. The behavior of self-compacting concrete containing micro-encapsulated phase change materials. Cement and Concrete Composites, 31 (10), $731-743$.

ISO, 1996. 8301, Thermal insulation - determination of steadystate thermal resistance and related properties - heat flow meter apparatus, international organization for tandardization. Geneva: ISO.

Karlessi, T., et al., 2011. Development and testing of PCM doped cool colored coatings to mitigate urban heat island and cool buildings. Building and Environment, 46 (3), 570-576.

Keikha, P., Hall, M., and Dawson, A., 2010. Concrete pavements as a source of heating and cooling. Proceeding 11th International Symposium on Concrete Roads, 13-15 October, Seville, Spain.

Kumar, R. and Bhattacharjee, B., 2003. Porosity, pore size distribution and in situ strength of concrete. Cement and Concrete Research, 33 (1), 155-164.

Mehling, H. and Cabeza, L.F., 2008. Heat and cold storage with $P C M$. Berlin: Springer.

Neville, A.M., 1995. Properties of concrete. Essex: Longman Group Limited.

Tyagi, V.V. and Buddhi, D., 2007. PCM thermal storage in buildings: a state of art. Renewable and Sustainable Energy Reviews, 11 (6), 1146-1166.

Yavuzturk, C., Ksaibati, K., and Chiasson, A.D., 2005. Assessment of temperature fluctuations in asphalt pavements due to thermal environmental conditions using a twodimensional, transient finite-difference approach. Journal of Materials in Civil Engineering, 17 (4), 465-475.

Zhang, D., et al., 2004. Development of thermal energy storage concrete. Cement and Concrete Research, 34 (6), 927-934. 